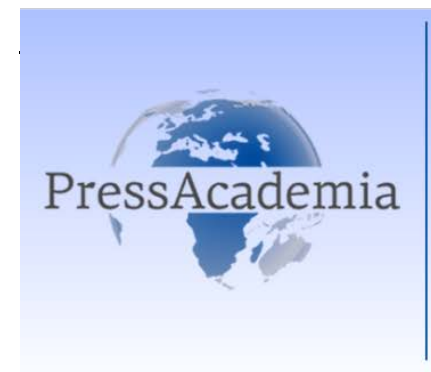

Press Academia Procedía

Global Business Research Congress (GBRC), June 4-5, 2015, Istanbul, Turkey.

\title{
ERGONOMIC ANALYSIS OF WORKING POSTURES THAT CAUSE STRAIN ON WORKERS THAT WORK IN HAND PLACEMENT BUSINESS OF TRANSPORTING CONTAINERS
}

DOI: 10.17261/Pressacademia.2016118133

\author{
Hakan Yetim ${ }^{1}$, Tulin Gunduz ${ }^{2}$ \\ ${ }^{1}$ Işı Üniversitesi. hakan.yetim@isikun.edu.tr \\ Uludağ Üniversitesi. tg@uludag.edu.tr
}

\begin{abstract}
Due to increased competition in the globalized world, technological innovations and higher production rates have become very important for businesses. Despite advances and innovations in technology, the employees who work in countries which have developed industry resulting musculoskeletal disorders causes serious economic losses, it has been shown to affect the entire community rather than individuals in it. Reducing the fatigue and stress consists physical overloading on human provides significant contributions on productivity and labor costs. To be understanding of this situation emerges the importance of working stance. Today has started to benefit from the ergonomic analysis for the elimination of all actions and activities that do not contribute to production. Poor posture is observed during the some works such as hand placement business of transporting containers. For study of analysis, these works are selected and the methods of REBA and BAUA are benefited to investigate the posture of employees during work. BAUA analysis method cares about all body posture, carried load and time of carrying but REBA analysis method considers also the score of stance of upper limb. In this study, REBA and BAUA ergonomic analysis methods are evaluated by comparing to learn what the results are in a predetermined process
\end{abstract}

Keywords: Health management, ergonomics, REBA, BAUA, working postures.

JEL Codes: I10, L62

\section{TAŞIMA KAPLARININ ELLE YERLEŞTIRILMESINDE ZORLANMAYA NEDEN OLAN ÇALIŞMA DURUŞLARININ ANALIZI}

\section{ÖZET}

Globalleşen dünyada rekabetin artmasına bağlı olarak, teknolojik yenilikler ve daha yüksek üretim hızları işletmeler için büyük önem kazanmıştır. Teknolojideki ilerlemeler ve yeniliklere rağmen sanayileri gelişmiş ülkelerdeki iş görenlerde meydana gelen kas iskelet sistemi rahatsızlıklarının ciddi ekonomik kayıplara neden olduğu, bununda bireylerden ziyade toplumun tamamını etkilediği görülmüştür. İnsan üzerinde fiziksel yüklenme sonucu oluşan yorgunluk ve iş stresinin azaltılmasının verimliliğe ve maliyete büyük katkılar sağladığının anlaşılması ile çalışma duruşlarının önemi de ortaya çıkmıştır. Günümüzde üretime katkısı olmayan tüm eylem ve faaliyetlerin ortadan kaldırılması için ergonomik analizlerden yararlanılmaya başlanmıştır. Yapılan çalışmada kötü duruşların çok olduğu gözlemlenen taşıma kaplarının elle yerleştirmesi işi seçilmiş ve iş görenlerin çalışma duruşlarının incelenmesi için REBA ve BAUA analiz metotlarından yararlanılmıştır. BAUA analiz yöntemi tüm vücut duruşları ile taşınılan yüke ve süresine önem verirken REBA analiz yöntemi üst uzuvların duruşlarına ait puanlarının da hesaplamaya katılmasını sağlamaktadır. Bu çalışmada, REBA ve BAUA ergonomi analiz yöntemlerinin, önceden belirlenen bir proseste nasıl sonuçlar verdiği karşılaştırılarak değerlendirilmiştir.

Anahtar Kelimeler: Sağlık yönetimi, ergonomi, REBA, BAUA, çalışma duruşları.

JEL Kodlları: I10, L62 


\section{GiRiş}

Küreselleşen dünyada teknolojinin hızla ilerlemesi ve bilişim çağının başlaması, hayatın birçok alanında işleri kolaylaştırdığı gibi, üretim anlayışını da değiştirmiştir. Makinelerin üretimdeki yeri her geçen gün artmaktadır. Bu durum, işleri hızlandırmakta ve kolaylaştırmaktadır. Diğer yandan, hala birçok işletmede emek yoğun üretim sürmekte ve çalışanlar yoğun fiziksel yüklenmelerle karşılaşmaktadırlar. Hem makinelerle çalışan operatörlerde, hem de emek yoğun çalışan ağır yük işçilerinde, kas-iskelet sistemi hastalıkları olarak adlandırılan sırt, boyun, bilek, kol ve bacak ağrıları yaygın bir şekilde görülmektedir (Kocabaş, 2009).

Ergonominin amacı öncelikle iş görenlerin çalışma koşullarını iyileştirerek, yaralanmaları ve hastalıkları engellemek; iş verimini yükselterek kazancı artırmak ve yatırımın geri dönüşünü hızlandırmaktır. Ergonominin birçok tanımı vardır. Ergonomiyi kısaca; oluşabilecek tüm fizyolojik ve psikolojik stresler karşısında insanmakine-çevre uyumunu sağlamaya çalışan bir bilim dalı olarak tanımlanabilir.

Günümüzde ergonomi, iş görenin çalışma ve yaşam kalitesini yükseltmek amacıyla, sağlığının ve güvenliğinin korunması, iyileştirilmesi ve iş veriminin artırılmasına yönelik olarak çalışma yaşamında ve günlük yaşamda kullanılan her türlü araç ve gerecin kişiye uydurulması için yapılan tüm faaliyetleri kapsamaktadır. Ergonomi, kalitenin ve verimliliğin önündeki engelleri kaldırır. Ergonomi; çalışan için çalışma ve yaşam kalitesini yükselmesi, özellikle kas-iskelet sistemi sağlığının iyileştirilmesi, işveren için verimliliğin ve karlılığın artması demektir (Akay vd. 2003).

Emek yoğun üretim sistemlerinde ergonominin üzerinde durduğu konulardan biri de çalışma duruşlarıdır. Duruş (Postür) iş aktivitelerinin yapıldığı esnada mevcut olan vücut pozisyonudur. Eklemlerin, vücudun çalışması esnasında en az zorlandığı ve enerji harcandığı pozisyon, nötral pozisyon olarak tanımlanmaktadır. Omurga ve her eklem için belirli olan nötral pozisyonun sağlanması ve korunması bel, sırt, boyun ve tüm eklemlerin sağlığının temelini oluşturmaktadır. Hastalıkların tedavisinde ve önlenmesinde iş yerinin ergonomik olarak düzenlenmesi önem taşımaktadır (Yılmaz ve ark. 2006).

Uygulamada çalışma duruşlarının analizi için kullanılan birçok metot mevcuttur. Bu çalışmada REBA (Rapid Entire Body Assessment)' ve BAUA(Federal Institute for Occupational Safety and Health) metodları kullanılarak taşıma kaplarının elle raflara yerleştirilmesi işinin analizi ve karşılaştırması yapılmıştır.

\section{METOT}

\subsection{REBA Yöntemi}

REBA yöntemi, bir çalışma duruşu esnasında gövdede, boyunda, bacaklarda, üst kollarda, alt kollarda ve bileklerde ortaya çıkan fleksiyon ve ekstansiyonlara ve bu duruşlar esnasında çalışanın maruz kaldığı yüklere bağlı olarak 1 ile 15 arasında değişen bir skor belirlemektedir (Hignett ve McAtamney, 2000). REBA yöntemine göre bir çalışma duruşunun REBA skoru belirlenirken öncelikle vücut kısımları, A ve B Grubu olmak üzere ikiye ayrılır.

A Grubu: Gövde, Boyun, Bacaklar

B Grubu: Üst kollar, Alt Kollar, Bilekler

Gövde, Boyun ve Bacakların ayrı ayrı skorları belirlenerek, Tablo A yardımıyla bu skorların bir kombinasyonundan oluşan bir skor belirlenir. Bu skora Yük/Kuvvet skoru eklenerek A Skoru elde edilir.

Üst kol, Alt kol ve Bileklerin ayrı ayrı skorları belirlenerek, Tablo B yardımıyla bu skorların bir kombinasyonundan oluşan bir skor belirlenir. Bu skora Kavrama skoru eklenerek B Skoru elde edilir.

Daha sonra Tablo C kullanılarak, A ve B skorlarının bir kombinasyonundan oluşan C Skoru elde edilir. C Skoruna Aktivite skorunun ilave edilmesiyle REBA Skoru elde edilmiş olur.

Çalışmada analiz edilen duruşlar Şekil 1'de görüldüğü gibidir. Bu metotta gerçekleştirilen adımlar aşağıda verilmiştir. 

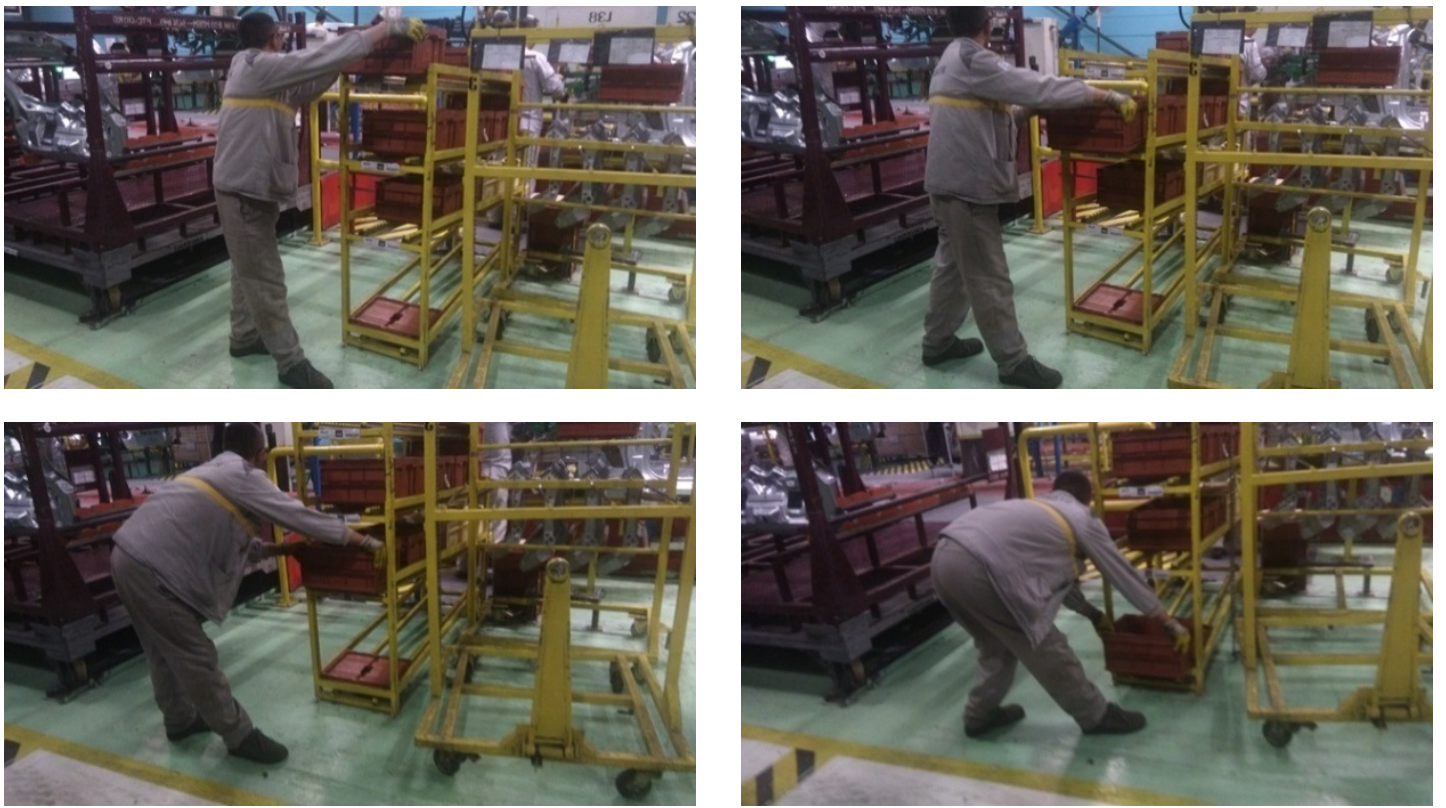

Şekil 1. Çalışmada analiz edilen duruşlar

Tablo 1'den gövde skoru 3 (2+1) olarak belirlenmiştir. Tablo 2'den boyun skoru $2(1+1)$ olarak belirlenmiştir. Tablo 3'den bacak skoru 1 olarak belirlenmiştir. Elde edilen değerler Tablo 4'de görülen A tablosuna yerleştirilir ve boyun skoru 1, bacak skoru 1 ve gövde skoru 3'e karşılık gelecek şekilde A tablosundan 4değeri okunur. A tablosu ile belirlenen bu skora Tablo 5'de görülen ve değeri 1 olarak belirlenen yük/kuvvet skoru eklenerek $A$ skoru elde edilir. Elde edilen değerlere göre A skoru 4+1 = 5 olarak belirlenmiştir.

Tablo 1: Gövde skoru

\begin{tabular}{|l|l|l|}
\hline Hareket & Skor & Skor değişimi \\
\cline { 1 - 2 } Dik & 1 & \multirow{2}{*}{$\begin{array}{l}\text { Yana esneme veya } \\
\text { dönme varsa +1 }\end{array}$} \\
\cline { 1 - 2 } $\begin{array}{l}0^{\circ}-20^{\circ} \text { Fleksiyon (germe) } \\
0^{\circ}-20^{\circ} \text { ekstansiyon(bükme) }\end{array}$ & 2 & \\
\cline { 1 - 2 } $\begin{array}{l}20^{\circ}-60^{\circ} \text { fleksiyon } \\
>20^{\circ} \text { ekstansiyon }\end{array}$ & 3 & \\
\hline$>60^{\circ}$ fleksiyon & 4 & \\
\hline
\end{tabular}

Tablo 2: Boyun skoru

\begin{tabular}{|l|l|l|}
\hline Hareket & Skor & Skor değişimi \\
\hline $0^{\circ}-20^{\circ}$ fleksiyon & 1 & $\begin{array}{l}\text { Yana esneme veya dönme varsa } \\
+1\end{array}$ \\
\cline { 1 - 2 } $20^{\circ}$ fleksiyon veya ekstensiyon & 2 & \\
\hline
\end{tabular}


Tablo 3: Bacak skoru

\begin{tabular}{|l|l|l|}
\hline Hareket & Skor & Skor değişimi \\
\hline $\begin{array}{l}\text { Bilateral (iki taraflı) ağırıı } \\
\text { taşıma, yürüme veya oturma }\end{array}$ & 1 & $\begin{array}{l}\text { Dizlerde } 30^{\circ}-60^{\circ} \text { arası fleksiyon+1 } \\
\text { Dizlerde }>60^{\circ} \text { fleksiyon (oturma hariç) } \\
+2\end{array}$ \\
\cline { 1 - 1 } $\begin{array}{l}\text { Unilateral (tek taraflı) ağırlık } \\
\text { taşıma veya sabit olmayan duruş }\end{array}$ & 2 & \\
\hline
\end{tabular}

Tablo 4: A Tablosu

\begin{tabular}{|c|c|c|c|c|c|c|c|c|c|c|c|c|c|}
\hline & \multicolumn{12}{|c|}{ BOYUN } \\
\hline & & \multicolumn{4}{|c|}{1} & \multicolumn{4}{|c|}{2} & \multicolumn{4}{|c|}{3} \\
\hline & & \multicolumn{4}{|c|}{ BACAKLAR } & \multicolumn{4}{|c|}{ BACAKLAR } & \multicolumn{4}{|c|}{ BACAKLAR } \\
\hline & & 1 & 2 & 3 & 4 & 1 & 2 & 3 & 4 & 1 & 2 & 3 & 4 \\
\hline \multirow{5}{*}{ : } & 1 & 1 & 2 & 3 & 4 & 1 & 2 & 3 & 4 & 3 & 3 & 5 & 6 \\
\hline & 2 & 2 & 3 & 4 & 5 & 3 & 4 & 5 & 6 & 4 & 5 & 6 & 7 \\
\hline & 3 & 2 & 4 & 5 & 6 & 4 & 5 & 6 & 7 & 5 & 6 & 7 & 8 \\
\hline & 4 & 3 & 5 & 6 & 7 & 5 & 6 & 7 & 8 & 6 & 7 & 8 & 9 \\
\hline & 5 & 4 & 6 & 7 & 8 & 6 & 7 & 8 & 9 & 7 & 8 & 9 & 9 \\
\hline
\end{tabular}

Tablo 5: Yük/kuvvet skoru

\begin{tabular}{|l|c|}
\hline Yük/kuvvet & Skor \\
\hline$<5 \mathrm{~kg}$ & 0 \\
\hline $\mathbf{5 - 1 0} \mathrm{kg}$ & $\mathbf{1}$ \\
\hline$>10 \mathrm{~kg}$ & 2 \\
\hline Ani veya hızlı kuvvet artışı & +1 \\
\hline
\end{tabular}

Tablo 6'dan üst kol skoru 5 (4+1) olarak belirlenmiştir. Tablo 7'den Alt kol skoru 2 olarak belirlenmiştir. Tablo 8'den bilek skoru $3(2+1)$ olarak belirlenmiştir. Elde edilen değerler B tablosuna yerleştirilir. Tablo 9'de görülen B tablosundan, alt kol skoru 2, bilek skoru 3 ve üst kol skoru 5'e karşılık gelecek şekilde 8 değeri bulunur.

Tablo 6: Üst kollar

\begin{tabular}{|c|c|c|}
\hline Hareket & Skor & Skor değişimi \\
\hline $20^{\circ}$ fleksiyon $-20^{\circ}$ ekstansiyon & 1 & \multirow{4}{*}{$\begin{array}{l}\text { Kolda: } \\
\text {-Abdüksiyon varsa } \\
\text {-Rotasyon varsa }+1 \\
\text {-Omuz yükselmişse }+\mathbf{1} \\
\text {-Kolun duruşunda yerçekimi desteği etkili ise }+1\end{array}$} \\
\hline $20^{\circ}-45$ fleksiyon $>20^{\circ}$ ekstansiyon & 2 & \\
\hline $45-90^{\circ}$ fleksiyon & 3 & \\
\hline$>90^{\circ}$ fleksiyon & 4 & \\
\hline
\end{tabular}


Tablo 7: Alt kol skoru

\begin{tabular}{|l|c|}
\hline Hareket & Skor \\
\hline $60^{\circ}-100^{\circ}$ Fleksiyon & 1 \\
\hline$<60^{\circ}-100^{\circ}$ fleksiyon veya $>100^{\circ}$ fleksiyon & 2 \\
\hline
\end{tabular}

Tablo 8: Bilek skoru

\begin{tabular}{|c|c|c|}
\hline Hareket & Skor & Skor değişimi \\
\hline $0^{\circ}-15^{\circ}$ fleksiyon veya ekstensiyon & 1 & \multirow{2}{*}{$\begin{array}{l}\text { Bileklerde yana esneme veya dönme } \\
\text { varsa }+1\end{array}$} \\
\hline$>15^{\circ}$ fleksiyon veya ektensiyon & 2 & \\
\hline
\end{tabular}

Tablo 9. B tablosu

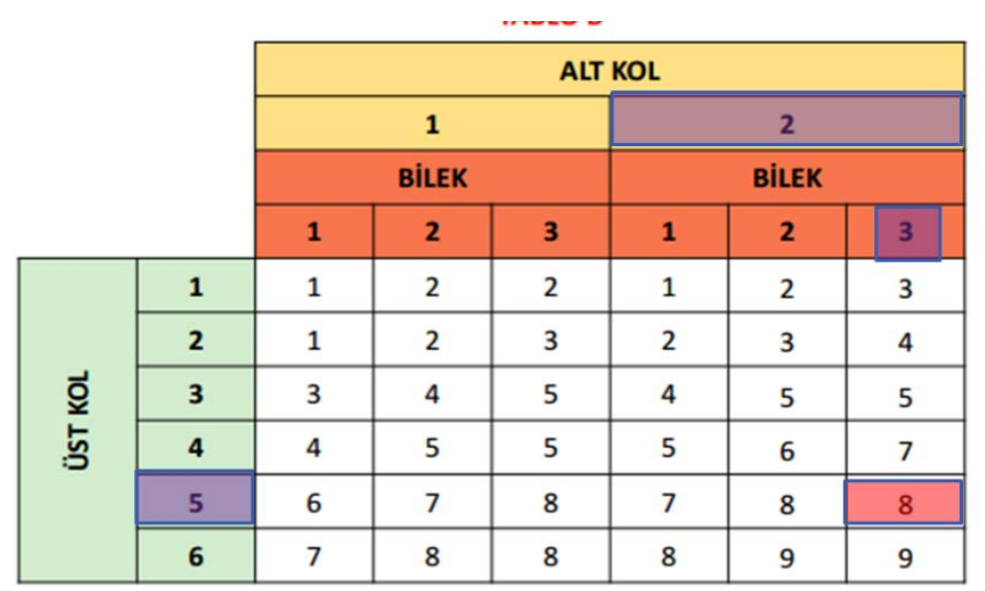

B tablosu ile belirlenen bu skora Tablo 10'da görülen kavrama skoru eklenerek B skoru elde edilir. Kavrama skoru olarak 2 değeri belirlenmiştir. Buradan B skoru $=8+2=10$ olarak elde edilir.

Tablo 10: Kavrama skoru

\begin{tabular}{|l|l|c|}
\hline Derece & Açıklama & Skor \\
\hline İyi & İyi bir tutma kolu ve orta şiddette kavrama gücü & 0 \\
\hline Uygun & $\begin{array}{l}\text { El tutuşu uygun fakat ideal değil veya vücudun başka } \\
\text { bir bölgesi ile kavrama uygun }\end{array}$ & 1 \\
\hline Kötü & El tutuşu uygun olmamasına rağmen mümkün & $\mathbf{2}$ \\
\hline Uygun değil & $\begin{array}{l}\text { Zor ve güvenli olmayan tutuş, tutma kolu yok } \\
\text { Vücudun başka bir bölgesi kullanılarak tutuş uygun } \\
\text { değil }\end{array}$ & 3 \\
\hline
\end{tabular}


Tablo 11'de görülen C tablosundan A skoru ve B skoruna karşılık gelen değerler kesiştirilerek $C$ skoru elde edilir. C tablosundan, A skoru 5 ve B skoru 10'a karşılık gelecek şekilde 9 değeri bulunur.

Tablo 11: C tablosu

\begin{tabular}{|c|c|c|c|c|c|c|c|c|c|c|c|c|c|}
\hline & \multicolumn{12}{|c|}{ B SKORU } \\
\hline & & 1 & 2 & 3 & 4 & 5 & 6 & 7 & 8 & 9 & 10 & 11 & 12 \\
\hline \multirow{12}{*}{ 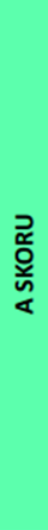 } & 1 & 1 & 1 & 1 & 2 & 3 & 3 & 4 & 5 & 6 & 7 & 7 & 7 \\
\hline & 2 & 1 & 2 & 2 & 3 & 4 & 4 & 5 & 6 & 6 & 7 & 7 & 8 \\
\hline & 3 & 2 & 3 & 3 & 3 & 4 & 5 & 6 & 7 & 7 & 8 & 8 & 8 \\
\hline & 4 & 3 & 4 & 4 & 4 & 5 & 6 & 7 & 8 & 8 & 9 & 9 & 9 \\
\hline & 5 & 4 & 4 & 4 & 5 & 6 & 7 & 8 & 8 & 9 & 9 & 9 & 9 \\
\hline & 6 & 6 & 6 & 6 & 7 & 8 & 8 & 9 & 9 & 10 & 10 & 10 & 10 \\
\hline & 7 & 7 & 7 & 7 & 8 & 9 & 9 & 9 & 10 & 10 & 11 & 11 & 11 \\
\hline & 8 & 8 & 8 & 8 & 9 & 10 & 10 & 10 & 10 & 10 & 11 & 11 & 11 \\
\hline & 9 & 9 & 9 & 9 & 10 & 10 & 10 & 11 & 11 & 11 & 12 & 12 & 12 \\
\hline & 10 & 10 & 10 & 10 & 11 & 11 & 11 & 11 & 12 & 12 & 12 & 12 & 12 \\
\hline & 11 & 11 & 11 & 11 & 11 & 12 & 12 & 12 & 12 & 12 & 12 & 12 & 12 \\
\hline & 12 & 12 & 12 & 12 & 12 & 12 & 12 & 12 & 12 & 12 & 12 & 12 & 12 \\
\hline
\end{tabular}

C tablosu ile belirlenen bu skora Tablo 12'de görülen aktivite skoru eklenerek REBA skoru elde edilir. Aktivite skoru +1 olarak belirlenmiştir.

Tablo 12: Aktivite skoru

\begin{tabular}{|l|c|}
\hline Aktivite & Skor \\
\hline $\begin{array}{l}\text { Bir veya daha fazla vücut bölgesi sabit } \\
\text { (örn: } 1 \text { dakikadan uzun süre tutma ) }\end{array}$ & +1 \\
\hline $\begin{array}{l}\text { Kısa aralıklarla tekrar eden işler } \\
\text { ( örn: } 1 \text { dakikada 4' ten fazla tekrar eden iş, yürüme hariç ) }\end{array}$ & $+\mathbf{1}$ \\
\hline $\begin{array}{l}\text { Yapılan iş duruşta hızlı ve büyük değişikliğe neden oluyorsa veya sabit } \\
\text { Olmayan zeminde çalışılıyorsa }\end{array}$ & +1 \\
\hline
\end{tabular}

Sonuç olarak REBA skoru $9+1$ = 10 olarak elde edilmiştir. Tablo 13’e göre, Reba skoru 10 olduğu için, risk derecelendirmesindeki puanı 3 , risk seviyesi yüksek olarak bulunmuştur.

Tablo 13: REBA risk derecelendirme tablosu

\begin{tabular}{|l|l|l|l|}
\hline Derece & Reba skoru & Risk seviyesi & Önlem \\
\hline 0 & 1 & İhmal Edilebilir & Gerekli Değil \\
\hline 1 & $2-3$ & Düşük & Gerekli Olabilir \\
\hline 2 & $4-7$ & Orta & Gerekli \\
\hline $\mathbf{3}$ & $\mathbf{8 - 1 0}$ & Yüksek & Kısa Zaman İçerisinde Gerekli \\
\hline 4 & $11-15$ & Çok Yüksek & Hemen Gerekli \\
\hline
\end{tabular}




\subsection{BAUA Yöntemi}

Federal Almanya i̇ş Güvenliği ve İş Hekimliği Kurumu (BAUA) tarafından;1999 yılında yeni bir yöntem geliştirmiştir. Bu yöntemle, kaldırma, tutma, taşıma, işlemlerinde çalışan personelin ne kadar zorlandığını belirlemek mümkündür. BAUA yönteminin amacı, elle yapılan taşıma işlemlerinde zorlanma sınırının iş bilimsel ölçütlere göre saptanmasında pratiğe yönelik, basit yasal, zorunlulukları yerine getiren ve çok boyutlu bir değerlendirmeye imkân sağlamaktadır(Babalık, 2005). Bu yöntem tıbbı ve işbilimsel bakış açılarının yanı sıra çalışma koşullarının sosyal ve iş yasalarına uygunluğunun saptanmasında yardımcı bir yöntemdir. Yöntem üç adımdan oluşmaktadır.

1. Adım: Yüklenmenin günlük çalışma süresi içindeki tekrarlanma sıklığına göre zaman aralığının belirlenmesi,

2. Adım: Kaldırılan yük, vücudun duruş şekli ve çalışma koşullarına göre zorlanma ağırlıklarının belirlenmesi,

3. Adım: Değerlendirme

1.Adım: Zaman Ağırlığının Belirlenmesi. Öncelikle Tablo 14'de görüldüğü gibi iş süresi ve ağırlık derecesi belirlenir. Bir günde yapılan iş sayısı ortalama 946 olduğu için, zaman ağırlığı tabloda görüldüğü gibi 8 olarak seçilmiştir.

Tablo 14: İş süresi ve ağırlık derecesi

\begin{tabular}{|c|c|c|c|c|c|}
\hline \multicolumn{2}{|c|}{$\begin{array}{l}\text { Kaldırma ve yer değiştirme } \\
(<5 \mathrm{~s})\end{array}$} & \multicolumn{2}{|c|}{$\begin{array}{l}\text { Tutma } \\
\text { (>5s) }\end{array}$} & \multicolumn{2}{|c|}{$\begin{array}{l}\text { Taşıma } \\
(>5 \mathrm{~m})\end{array}$} \\
\hline $\begin{array}{l}\text { Bir günde } \\
\text { yapılan iş } \\
\text { sayısı }\end{array}$ & $\begin{array}{l}\text { Zaman } \\
\text { ağırlığı }\end{array}$ & $\begin{array}{l}\text { Bir günde } \\
\text { toplam süre }\end{array}$ & $\begin{array}{l}\text { Zaman } \\
\text { ağırlığı }\end{array}$ & $\begin{array}{l}\text { Bir günde toplam } \\
\text { mesafe }\end{array}$ & Zaman ağırlığı \\
\hline$<10$ & 1 & $<5 \mathrm{dk}$ & 1 & $<300 m$ & 1 \\
\hline $10 \ldots .40$ & 2 & $5.15 \mathrm{dk}$ & 2 & $300 \mathrm{~m} .1 \mathrm{~km}$ & 2 \\
\hline $40 \ldots .200$ & 4 & $15 \mathrm{dk} 1 \mathrm{~s}$ & 4 & $1 \ldots 4 \mathrm{~km}$ & 4 \\
\hline $200 \ldots . .500$ & 5 & 1.2 saat & 6 & $4 \ldots 8 \mathrm{~km}$ & 6 \\
\hline $500 \ldots 1000$ & 8 & 2..4 saat & 8 & $8 \ldots . .16$ km & 8 \\
\hline$\geq 1000$ & 10 & $\geq 4$ saat & 10 & $\geq 16 \mathrm{~km}$ & 10 \\
\hline
\end{tabular}

2.Adım: Yük, tutma ve uygulama şartlarının ağırlıklarının belirlenmesi. İşi yapan kişinin erkek ve etken kuvvetin 16 kg olması sebebi ile, yük önemliliği Tablo 15'den 2 olarak seçilmiştir. Vücudun öne eğilmesi fazla olduğu için, konum ağırlık derecesi Tablo 16'de görüldüğü gibi 8 olarak seçilmiştir. İyi ergonomik koşullar, yeterli alan, engelsiz çalışma alanı, düz kaymayan zemin, yeterli aydınlatma, tutabilme iyi ve kolay olduğu için, uygulama koşulları ağırlık derecesi Tablo 17'den 0 olarak seçilmiştir. 
Tablo 15: Etken kuvvetler ve önemlilik derecesi

\begin{tabular}{|l|c|c|c|}
\hline $\begin{array}{l}\text { Etken kuvvet } \\
\text { (erkekler için) }\end{array}$ & $\begin{array}{c}\text { Yük } \\
\text { Önemliliği }\end{array}$ & $\begin{array}{c}\text { Etken kuvvet } \\
\text { (kadınlar için) }\end{array}$ & $\begin{array}{c}\text { Yük } \\
\text { Önemliliği }\end{array}$ \\
\hline$<10 \mathrm{~kg}$ & 1 & $<5 \mathrm{~kg}$ & 1 \\
\hline $10 \ldots . .20 \mathrm{~kg}$ & $\mathbf{2}$ & $5 \ldots .10 \mathrm{~kg}$ & 2 \\
\hline $20 \ldots . .30 \mathrm{~kg}$ & 4 & $10 \ldots .15 \mathrm{~kg}$ & 4 \\
\hline $30 \ldots . .40 \mathrm{~kg}$ & 7 & $15 \ldots .25 \mathrm{~kg}$ & 7 \\
\hline$\geq 40 \mathrm{~kg}$ & 25 & $\geq 25 \mathrm{~kg}$ & 25 \\
\hline
\end{tabular}

3. Adım: Değerlendirme Sonuç Tablosu. Bu adımda, daha önce bulunan yük önemliliği, konum ağırlığı ve uygulama şartları değerşeri toplanıp, zaman ağırlığı ile çarpılır.

$(2+8+0) \times 8=80$ Elde edilen değer risk tablosuna yerleştirilir (Tablo 18).

Tablo 18'e göre risk faktörü değeri 80 olduğu için, değerlendirme tablosundaki risk bölgesi 4 olarak belirlenmiştir. Bu duruma göre, risk çok fazla olduğu için çalışanın vücudunun zorlanması kaçınılmazdır. İş düzenlemesinde iyileştirme önlemleri acilen ve mutlaka alınmalıdır.

\section{Tablo 16: Konum ve ağılık derecesi}

\begin{tabular}{|c|c|c|}
\hline $\begin{array}{l}\text { Karekteristik Vücut Konumları } \\
\text { ve Yük Pozisyonları }\end{array}$ & Vücut Duruşu, yükün pozisyonu & $\begin{array}{l}\text { Konum } \\
\text { ağırlığı }\end{array}$ \\
\hline & $\begin{array}{l}\text {-Gövdenin üstü dik, döndürülmüyor. } \\
\text { - Yük gövdede }\end{array}$ & \\
\hline & $\begin{array}{l}\text { Çok hafif eğilme veya üst gövdenin döndürülmesi } \\
\text { - Yük gövdede veya gövde yakınında. }\end{array}$ & 2 \\
\hline & $\begin{array}{l}\text {-Aşağıya veya öne fazla eğilme } \\
\text {-Öne eğilirken gövdenin üst kısmının } \\
\text { döndürülmesi } \\
\text {-Yük gövdeden uzakta veya omuz yüksekliğinden } \\
\text { ileride }\end{array}$ & 4 \\
\hline & $\begin{array}{l}\text {-Öne doğru fazla eğilirken aynı zamanda } \\
\text { gövdenin üst kısmının döndürülmesi. } \\
\text {-Yük gövdeden uzakta } \\
\text {-Ayakta konumunu sabit tutabilmek } \\
\text { zor. } \\
\text {-Çömelme veya diz üzerine çökme. }\end{array}$ & 8 \\
\hline
\end{tabular}


Tablo 17: Uygulama koşulları ve ağırlık derecesi

\begin{tabular}{|l|c|}
\hline Uygulama Koşulları & Uygulama Ağırlığı \\
\hline $\begin{array}{l}\text { Iyyi ergonomik koşullar, örneğin yeterli alan, engelsiz çalışma } \\
\text { alanı, düz-kaymayan zemin, yeterli aydınlatma, tutabilme iyi ve } \\
\text { kolay }\end{array}$ & $\mathbf{0}$ \\
\hline $\begin{array}{l}\text { Hareket etme olanağı sınırlı, ergonomik koşullar kötü Örnek, } \\
\text { 1- alçak tavan ve } 1.5 \text { m2 den daha az çalışma alanı } \\
\text { 2- düz olmayan veya yumuşak zemin nedeniyle ayakta dururken } \\
\text { sendeleme, düşme olasılığı. }\end{array}$ & 1 \\
\hline $\begin{array}{l}\text { Hareket etme serbestliği çok sınıllanmış, veya yükün ağılılı } \\
\text { merkezinin değiş̧en olması }\end{array}$ & 2 \\
\hline
\end{tabular}

Tablo 18: Risk değerlendirme tablosu

\begin{tabular}{|c|c|l|}
\hline $\begin{array}{c}\text { Risk } \\
\text { Bölgesi }\end{array}$ & Risk Faktörü Değeri & Açıklama \\
\hline 1 & $<10$ & $\begin{array}{l}\text { Düşük yük, vücudun fazla yüklenmesi nedeniyle sağlı̆̆ın } \\
\text { kaybedilmesi olası değil }\end{array}$ \\
\hline 2 & $10 \ldots 25$ & $\begin{array}{l}\text { Biraz fazla yük, az yüklenebilen personel için vücudun fazla } \\
\text { zorlanması olası. Böyle personel için iş düzenlemesinde } \\
\text { iyileştirme önlemleri anlamlı olur }\end{array}$ \\
\hline 3 & $25 \ldots 50$ & $\begin{array}{l}\text { Epey fazla yük, normal yüklenebilir kişiler için de vücudun } \\
\text { fazla zorlanması olası. İ̧ düzenlemesini iyileştirme yönüne } \\
\text { gidilmeli }\end{array}$ \\
\hline $\mathbf{4}$ & $>\mathbf{5 0}$ & $\begin{array}{l}\text { Çok fazla yük, vücudun fazla zorlanma yüklenme olasıllı̆ı̆ } \\
\text { çok yüksek. İş düzenlemesinde iyileştirme önlemleri } \\
\text { almak şart }\end{array}$ \\
\hline
\end{tabular}

\section{SONUÇ}

Ergonomi konusu tıp bilimcilerinin, mühendislerin, iş bilimcilerin kısacası insan ve makine ile uğraşan tüm bilim dallarının ilgi alanına girmektedir. Bu nedenle konuyla ilgili birçok çalışma yapılmış ve analiz yöntemleri geliştirilmiştir. Ergonominin temel konularından bir tanesi iş görenlerin çalışma esnasındaki duruşlarıdır. Yapılan çalışmada kötü duruşların çok olduğu gözlemlenen taşıma kaplarının elle yerleştirmesi işi seçilmiş ve iş görenlerin çalışma duruşlarının incelenmesi için gözleme dayalı tekniklere dayanan REBA ve BAUA analiz metotlarından yararlanılmıştır. İki yöntem karşılaştııılı̆ı̆ında analiz sonuçlarında farkıııkların olduğu gözlemlenmiştir. Bu da analiz yöntemlerinin kullanım yerlerinin farklı olabileceğini ortaya koymaktadır. BAUA analiz yöntemi tüm vücut duruşları ile taşınılan yüke ve süresine önem verirken REBA analiz yöntemi üst uzuvların duruşlarına ait puanlarının da hesaplamaya katılmasını sağlamaktadır. Bu nedenle kullanılacak olan metodu seçerken yapılan işin ve iş göreninin duruş özellikleri önceden gözlemlenmeli ve uygun olan metot belirlenmelidir. Bu çalışmada olduğu gibi daha çok güç ve vücut kullanılarak yapılan işlerde BAUA yöntemi daha başarılı olacaktır. 


\section{KAYNAKÇA}

Akay, D., Dağdeviren, M., Kurt, M., 2003. Çalışma Duruşlarının Ergonomik Analizi. Gazi Üniversitesi Mühendislik Mimarlık Fakültesi Dergisi, 18:3, 73-84, Ankara.

Babalık, F. C., 2005. Mühendisler İçin Ergonomi İşbilimi. Nobel Yayın Dağıtım. Ankara.

Hignett, S., McAtamney, L., 2000. Rapid Entire Body Assessment (REBA). Applied Ergonomics. 31, 201-205.

Kocabaş, M. 2009. Ağır ve tehlikeli işlerde çalışan iş görenlerde zorlanmaya neden olan çalışma duruşlarının analizi. Yüksek Lisans Tezi. Selçuk Üniversitesi.

Yılmaz, F., Şahin, F., Kuran, B., 2006. İşe Bağlı Kas İskelet Hastalıkları ve Tedavisi. Nobel Medicus. 2: 3, 15-22. 